\title{
Characterization of Synthesized Titanium Oxide Nanoclusters by MALDI-TOF Mass Spectrometry
}

\author{
Bing Guan \\ Department of Chemistry, University of New Orleans, New Orleans, Louisiana, USA \\ Weigang Lu and Jiye Fang \\ Department of Chemistry and Advanced Materials Research Institute, University of New Orleans, \\ New Orleans, Louisiana, USA \\ Richard B. Cole \\ Department of Chemistry, University of New Orleans, New Orleans, Louisiana, USA
}

Titania represents an important material that has wide applications. The bactericidal efficiency of $\mathrm{TiO}_{2}$ has been shown to be dependent on the size of the nanoparticles, so it is important to be able to reliably estimate their dimensions. In this study, a stable $\mathrm{TiO}_{2}$ cluster suspension is produced by the thermal solvent process, and ultrasmall clusters $(<1 \mathrm{~nm})$ with different sizes are obtained by size-selection treatment. MALDI-TOF-MS and LDI-TOF-MS are shown to be useful for characterization of these ultrasmall nanoparticles. Peak maxima are found to correlate with nanoparticle size, and the possibility of using these mass spectrometry-based approaches to estimate nanoparticle size is affirmed. The size distributions of $\mathrm{TiO}_{2}$ nanoparticles obtained from MALDI- and LDI-TOF-MS are in good agreement with parallel TEM observations. Finally, PSD analysis of inorganic nanomaterials is performed and valuable information about the structure of analytes has been obtained. (J Am Soc Mass Spectrom 2007, 18, 517-524) @ 2007 American Society for Mass Spectrometry

$\mathrm{T}$ Titania (that is, species composed of titanium and oxygen) represents an important material that is used widely in photocatalysis [1-3], sensor technology [4], optical coatings [5], and pigments [6]. It has been used for the destruction of toxic organic compounds and microorganisms such as bacteria and viruses, in addition to its applications in purification of polluted air and wastewaters [2,3]. Titania's advantages over other materials are that it is relatively inexpensive, nontoxic, and it exhibits a high photostability in adverse environments, among other desirable surface properties. It is also being used in low-cost, highly efficient dye-sensitized solar cells [7, 8]. Titania itself has a relatively large band gap and is unable to absorb a significant part of the visible light spectrum. When coupled with suitable charge-transfer dyes, however, it can quantitatively convert visible light photons into electric current $[7,8]$. It has been widely used as a model transition-metal oxide because of its rather simple electronic structure, which is characterized by a filled valence band and an empty conduction band [9].

Published online November 30, 2006

Address reprint requests to Dr. Richard B. Cole, Department of Chemistry, University of New Orleans, 2000 Lakeshore Drive, New Orleans, LA 70148. E-mail: rcole@uno.edu
Cluster models have been frequently used in theoretical calculations of titanium dioxide bulk or surface properties [10-12]. However, for experimental study of titania clusters produced by evaporation and sputtering, it is difficult to achieve control over particle size, size distribution, and shape because the reactions of molecular precursors require rather high temperatures. There are many reports on isolated titanium (IV) nanoclusters produced by wet chemical methods [13, 14], although, to our knowledge, there are no reports on isolated stable nanoclusters with diameters $<1 \mathrm{~nm}$.

High-temperature organic solution phase synthesis is a very promising method to develop many nanocrystals with controlled shapes and sizes. In this method, one can control the growth of the nanoparticles by choosing the proper capping ligand. We seek to produce titania clusters by reaction of titanium alkoxide in a nonpolar solvent, along with an air- and water-free environment, because hydrolysis of titanium alkoxide is difficult to control if there are even trace amounts of water.

Both transmission electron microscopy (TEM) and powder X-ray diffraction (XRD) analyses are typically used to measure the shapes, sizes, and size distributions of nanocrystal samples. However, standard TEM instrumentation is not so readily adapted to the analysis 
of nanoparticles that are $<1 \mathrm{~nm}$ in size. First, it is statistically insignificant to infer average size and a size distribution for the ensemble by examining only a tiny region in a TEM image because the chosen areas of the grid may not be representative of the ensemble [15]. Second, it is not easy to definitively determine the boundary between the cluster and grid on a TEM image when cluster sizes are smaller than about 2-3 nm [15]. Moreover, changes in the size of clusters may occur during the drying process, possibly caused by, but not limited to, aggregation and chemical changes (such as oxidation or hydration). Fitting XRD data to the Scherer equation to calculate cluster size is of limited accuracy because the Scherer equation strictly applies only to uniformly shaped, noninteracting nanoparticles with an assigned distribution of sizes [15, 16].

Mass spectrometry (MS) represents an alternative means to determine sizes and size distributions of nanoparticles by obtaining accurate mass information. The mass spectra of nanoparticles will provide size information through calculation using the known particle density values. Also, valuable structural information may be obtained concerning nanoparticle composition through knowledge of fragmentation pathways and the relative abundances of nanoparticle components. Beyond its widely acknowledged applications in biological, molecular, and polymeric systems, MS has been successfully used to characterize various nanoparticles such as fullerenes [17, 18], silica clusters [19], metal chalcogenide clusters [20-24], gold nanocrystals [25-28], and several other nanomaterials [29-33].

Electrospray (ES) ionization [34, 35] coupled with tandem MS (MS/MS) has become a powerful tool for analyses of nanoparticle composition [22-24, 30, 36-38] provided that the nanoparticle can be suspended in a solvent of moderate polarity without decomposition or other reactions. Laser desorption/ionization time-of-flight mass spectrometry (LDI-TOF-MS) has also been used to record mass spectra and determine specific atomic compositions of large gold nanocrystals with masses of tens of kilodaltons without the use of matrices [25-28]. In sharp contrast, in the absence of suitable matrices, biological polymers such as proteins, DNAs, and carbohydrates, as well as large (for example, 10,000 Da) synthetic polymers tend to fragment under laser irradiation, thus making it very problematic to observe intact molecular ions. However, matrix-assisted laser desorption/ionization (MALDI) can be used for fast analyses of sizes and size distributions of nanoparticles when suitable matrices are found. Although not truly tandem MS, post-source decay (PSD) [39, 40] can provide additional valuable information about the structure of analytes observed by MALDI-TOF. Because $\mathrm{TiO}_{2}$ has been used as a photocatalyst for killing bacteriaand bactericidal efficiency has been shown to be dependent on the size of the nanoparticles present-the current study seeks to determine sizes and size distributions of ultrasmall $\mathrm{TiO}_{2}$ nanoparticles using MALDITOF and LDI-TOF mass spectrometry with PSD analy- sis. This report presents results of our synthesis and characterization of ultrasmall $\mathrm{TiO}_{2}$ nanoparticles (that is, $<1 \mathrm{~nm})$.

\section{Experimental}

\section{Materials}

All chemicals were purchased and used as received without further purification. Distilled, deionized water (Milli-Q Systems, Millipore Corp., Billerica, MA, USA) was used throughout. Matrices used in this experiment, dithranol, $\alpha$-cyano-4-hydroxycinnamic acid ( $\alpha$-CHCA), 2,5-dihydroxybenzoic acid (DHB), or sinapinic acid, were purchased from Aldrich Chemical (Milwaukee, WI, USA). Titanium tetrabutoxide $\left[\mathrm{Ti}\left(\mathrm{OC}_{4} \mathrm{H}_{9}\right)_{4}\right]$, trioctylamine $\left(\left[\mathrm{CH}_{3}\left(\mathrm{CH}_{2}\right)_{7}\right]_{3} \mathrm{~N}\right)$, benzyl ether, toluene, methanol, and chloroform were also purchased from Aldrich Chemical.

\section{Nanoparticle Preparation}

Titania clusters were prepared using titanium tetrabutoxide $\left[\mathrm{Ti}\left(\mathrm{OC}_{4} \mathrm{H}_{9}\right)_{4}\right]$ as the precursor and trioctylamine as the capping agent in a benzyl ether solvent with heating. Trioctylamine was chosen as the capping ligand because its three-dimensional structure may prevent smaller clusters from aggregating to form larger particles. The synthesis experiment was carried out in a three-neck flask equipped with a condenser and an argon stream. Typically, $1 \mathrm{~mL} \mathrm{Ti}\left(\mathrm{OC}_{4} \mathrm{H}_{9}\right)_{4}$ and $1 \mathrm{~mL}$ trioctylamine were added into $10 \mathrm{~mL}$ hot benzyl ether at $563 \mathrm{~K}$ with stirring for $24 \mathrm{~h}$; the color of the solution changed gradually from yellow to dark red as the reaction continued. The size-selection process involved centrifugation using a pair of solvents (that is, toluene and methanol) to obtain different-sized $\mathrm{TiO}_{2}$ clusters; the final products were redissolved in toluene. The term "raw nanoparticles" refers to precipitation without size selection throughout this paper. After size selection, the cluster sample suspensions appeared red, except for the raw nanoparticle suspensions, which were slightly gray. Although one could anticipate the formation of stoichiometric $\mathrm{Ti}_{\mathrm{x}} \mathrm{O}_{2 \mathrm{x}}$, when clusters are formed, there is usually a slight deviation from this strict 1:2 stoichiometry.

\section{$X R D$ and TEM}

XRD patterns were recorded using an X-ray diffractometer ( $\mathrm{Cu}-\mathrm{K} \alpha$, Philips X'pert systems, Natick, MA, USA). The $\mathrm{TiO}_{2}$ cluster suspensions were deposited onto a single Si substrate, and each diffraction pattern $(2 \theta=$ $20-80^{\circ}$ ) was scanned for $12 \mathrm{~h}$ because of the relatively low signal-to-noise ratio characteristic of $\mathrm{TiO}_{2}$ clusters. A JEOL-2010 (JEOL, Peabody, MA, USA) transmission electron microscope (TEM) operating at an accelerating voltage of $200 \mathrm{kV}$ was used to investigate the morphology of the raw clusters. 


\section{Mass Spectrometry}

Mass spectra were acquired on an Applied Biosystems Voyager Elite MALDI-TOF mass spectrometer with delayed extraction (Applied Biosystems, Framingham, MA, USA) equipped with a pulsed $\mathrm{N}_{2}$ laser $(\lambda=337 \mathrm{~nm})$. Either dithranol was used as the matrix, or no matrix at all was used, which implies laser desorption/ionization (LDI) in the latter case. An extraction voltage of $20 \mathrm{kV}$ was typically used. Laser intensity was adjusted to just above the threshold energy for appearance of titaniumcontaining ions except in PSD experiments where the energy was $20-30 \%$ higher. All mass spectra were acquired in the positive reflectron mode using delayed extraction. Each nanoparticle mass spectrum consists of an average of 50-100 laser shots. In preparation for MALDI, $3 \mu \mathrm{L}$ of nanoparticle suspension was mixed with $3 \mu \mathrm{L}$ of dithranol matrix in chloroform; then, $1 \mu \mathrm{L}$ of the mixture was deposited onto the MALDI plate and allowed to air dry. The diameters of the investigated particles were always smaller than the surface area illuminated by the laser beam, and thus data in the mass spectra originate from many individual nanoparticles. The instrument was externally calibrated using monoisotopic peaks from the dithranol matrix $\left(\mathrm{MH}^{+}\right.$at $\mathrm{m} / z$ 227.071) and from oxidized insulin chain $\mathrm{B}\left(\mathrm{MH}^{+}\right.$at $\mathrm{m} / \mathrm{z}$ 3494.651); angiotensin I was used for PSD calibration. Data processing was performed using IGOR Pro 4.07 (Wave Metrics, Lake Oswego, OR, USA).

\section{Results and Discussion}

When $\mathrm{Ti}_{x} \mathrm{O}_{2 x}$ clusters are formed, there is usually a small deviation from this exact stoichiometry, but for the purpose of this text, we will use the term " $\mathrm{TiO}_{2}$ " to represent the clusters. $\mathrm{TiO}_{2}$ nanoparticles are usually produced by hydrolysis of organometallic compounds. During the hydrolysis process, it is very easy to incur aggregation to form larger particles. In our case, $\mathrm{TiO}_{2}$ nanoclusters were produced by reaction of $\mathrm{Ti}\left(\mathrm{OC}_{4} \mathrm{H}_{9}\right)_{4}$ in a thermal solvent system. Trioctylamine was chosen as the capping ligand because its bulky three-dimensional structure may prevent smaller clusters from aggregating to form larger particles. Like most organometallic compounds, $\mathrm{Ti}\left(\mathrm{OC}_{4} \mathrm{H}_{9}\right)_{4}$ is highly moisture sensitive. The reaction was therefore carried out under an argon atmosphere. After reaction, post-treatment size selection was employed to allow tuning of the particle size and size distribution.

In the suspension of nanoparticles, the energetic barrier to aggregation caused by steric hindrance from capping ligands (such as trioctylamine used here) is strongly dependent on the energy of mixing between the tethered capping groups and the solvent. Introduction of a nonsolvent (methanol in this case), miscible with the original dispersing solvent (toluene), destabilizes the nanoparticle dispersions. The nanoparticles then "aggregate" and precipitate, leaving many of the synthetic by-products in solution. The resulting pow- ders may be redispersed in a variety of solvents, such as alkanes and aromatics, if the capping ligands are well bound to the surface of the nanoparticles. By using this treatment, fine-tuning of the particle size and size distribution can be achieved. After such size selection, the resulting $\mathrm{TiO}_{2}$ clusters (with capping ligands) were maintained in toluene where they exhibit good stability.

TEM images of the raw nanoparticles are shown in Figure 1; from these, we can estimate that the mean nanoparticle size is about $2.5 \mathrm{~nm}$ and that there are some elongated nanocrystals produced as well. The length of these less predominant elongated nanocrystals is about $5 \mathrm{~nm}$ with widths of approximately $1-2 \mathrm{~nm}$. Because of the projective nature of the TEM image, it is not straightforward to deduce the exact percentage of elongated particles versus spherical ones. The highresolution micrograph (Figure $1 \mathrm{~b}$ ) clearly shows that the lattice plane along the growth direction of the nanocrystals is (001). After size selection, the cluster dimensions could not be determined by TEM because the TEM employed is not capable of adequate resolution. For particles with even smaller size (estimated to be $<1 \mathrm{~nm}$ in our case), given the low contrast across the boundary between a cluster and the grid, high-quality TEM images are a challenge to obtain. The organic layer on cluster surfaces also affects the quality of TEM images. The organic groups at the cluster surface cannot be observed with electron beams, nor can the size of this organic group "shell" be determined [15].

$\mathrm{TiO}_{2}$ has seven different polymorphic forms, four of which are found in nature. The three common natural crystalline forms are: anatase, rutile, and brookite. All consist of octahedrally coordinated Ti cations arranged in edge-sharing chains, but they differ in the number of shared edges and corners. The octahedra in anatase share four edges and four corners, whereas the rutile $\mathrm{Ti}$ octahedral shares two edges and six corners and brookite $\mathrm{Ti}$ octahedral shares three edges and five corners $[6,41,42]$. Figure 2 shows the $\mathrm{XRD}$ patterns of $\mathrm{TiO}_{2}$ raw nanoparticles (curve A) and size-selected $\mathrm{TiO}_{2}$ clusters (curves $\mathrm{B}-\mathrm{D}$ ). According to the XRD data, all the peaks in curve A (raw nanoparticles) can be indexed as anatase $\mathrm{TiO}_{2}$ [43]. We estimated the raw anatase particle size using the Scherer equation [16]. On the basis of the (100) peak, the average particle size is $2.3 \mathrm{~nm}$, whereas on the basis of the (200) peak, it is $2.5 \mathrm{~nm}$. These estimations are in good agreement with the results from TEM observations except that there are some elongated nanocrystals observed in the TEM images. After size selection, there are large differences between XRD patterns. For curve B, the (200) peak becomes much broader compared with other peaks in this curve. However, the XRD pattern of curve $B$ can still be confidently indexed as the anatase phase of $\mathrm{TiO}_{2}$. The XRD patterns presented in curves $C$ and $D$ are extremely weak, peaks are broad, and the data are noisy. They are quite different from the XRD patterns of anatase and rutile, although the positions of the broad (200) peak maxima seem to coincide more with those of 

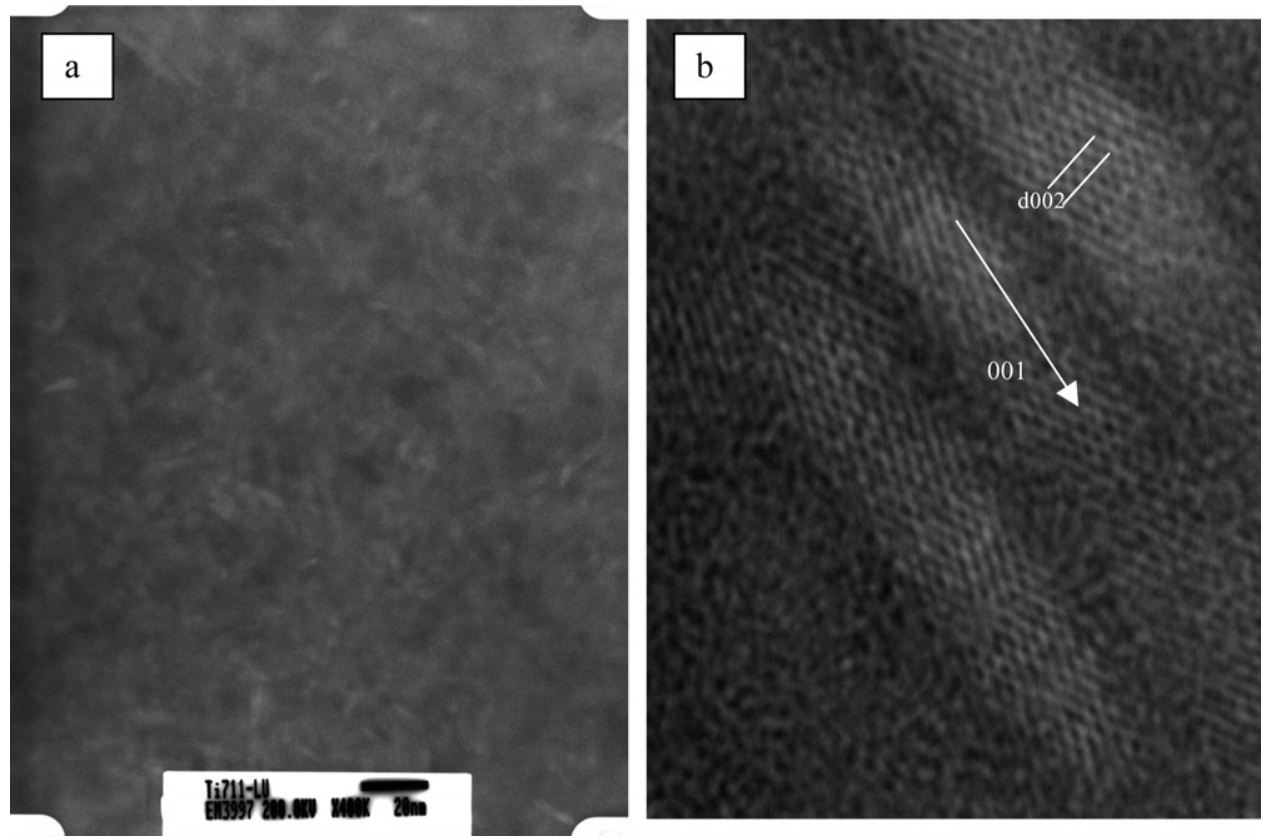

Figure 1. TEM images of anatase raw nanoparticles: (a) low-resolution TEM shows some elongated nanoparticles that are about $5 \times 1.5 \mathrm{~nm}$ in size; (b) high-resolution micrograph demonstrating elongated nanoparticles' growth along the [001] direction.

anatase. This suggests that long-range ordering structures in the size-selected clusters do not exist, and that the solids are essentially X-ray amorphous [6]. This may be caused by the extremely high surface area-to-volume ratio. Experimental $\mathrm{X}$-ray absorption fine-structure (XAFS) data show that $\mathrm{Ti}-\mathrm{O}$ bond lengths in nanocrystalline titanium dioxide are shorter than the bulk phase value of $1.94 \AA$, and can be as low as $1.79 \AA$ for surface atoms, as a result of $\mathrm{Ti}-\mathrm{OH}$ bonding [44, 45]. It was also reported that the curvature of the surface

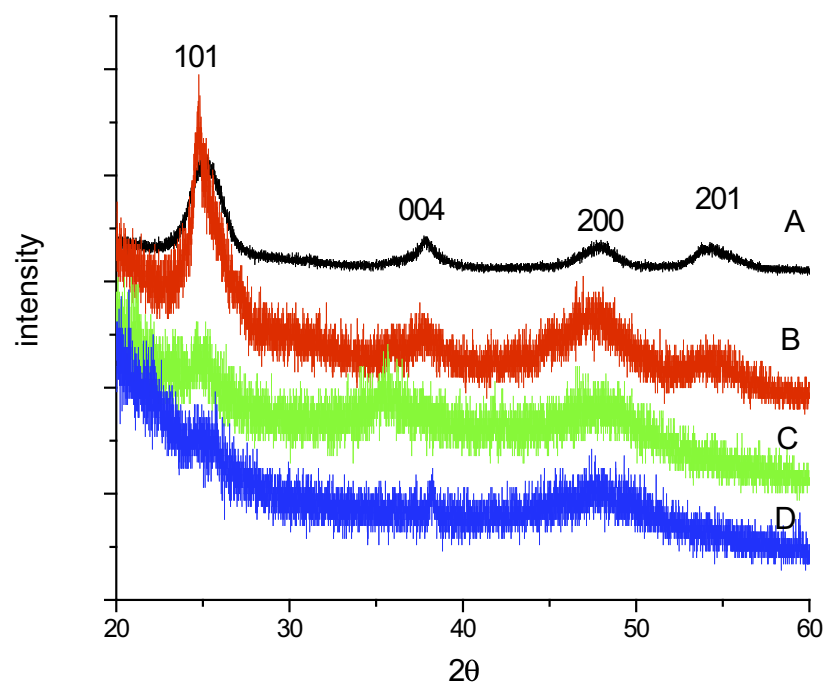

Figure 2. $\mathrm{XRD}$ patterns of raw $\mathrm{TiO}_{2}$ nanoparticles and sizeselected $\mathrm{TiO}_{2}$ clusters: Curve $\mathrm{A}$ is the pattern of nanoparticles that can be indexed as anatase; the size of the clusters decreases progressively from curve B to curve D. causes a decrease in the coordination number of the titanium ion from the normal octahedral environment (six) to where it has a coordination number of four or five [44-46]. According to the simulation of Naicker et al. [47] for small nanoparticles, the bulk phase structural features of $\mathrm{TiO}_{2}$ will exhibit decreased importance as the surface atoms make up a larger fraction of the total.

Initially, a limited effort was made to find appropriate matrices that would allow us to obtain MALDI-TOF mass spectra of the size-selected clusters. However, the use of several commonly used matrices [that is, $\alpha$-cyano-4hydroxycinnamic acid ( $\alpha$-CHCA), 2,5-dihydroxybenzoic acid (DHB), and sinapinic acid] failed to result in detection of titanium oxide ions; only matrix peaks were observed. In the presence of these organic acid matrices, the titanium oxide nanoparticles appeared to clump together, which makes the usual functions of the MALDI matrix (that is, isolation of analyte molecules and transfer of absorbed photon energy to analyte species) inefficient. Moreover, the use of methanol as solvent for these matrices was found to accelerate precipitation and aggregation (clumping) of the titanium oxides, further obscuring the ability to observe titanium oxide species in mass spectra.

The use of dithranol as the matrix, however, did yield signals representative of positively charged titanium oxide species. Unlike the above three organic acid matrices, dithranol lacks a strongly acidic group. Matrix solutions were prepared by dissolving $10 \mathrm{mg}$ of dithranol in $1 \mathrm{~mL}$ of dry chloroform without the use of methanol. Naturally occurring titanium is composed of 

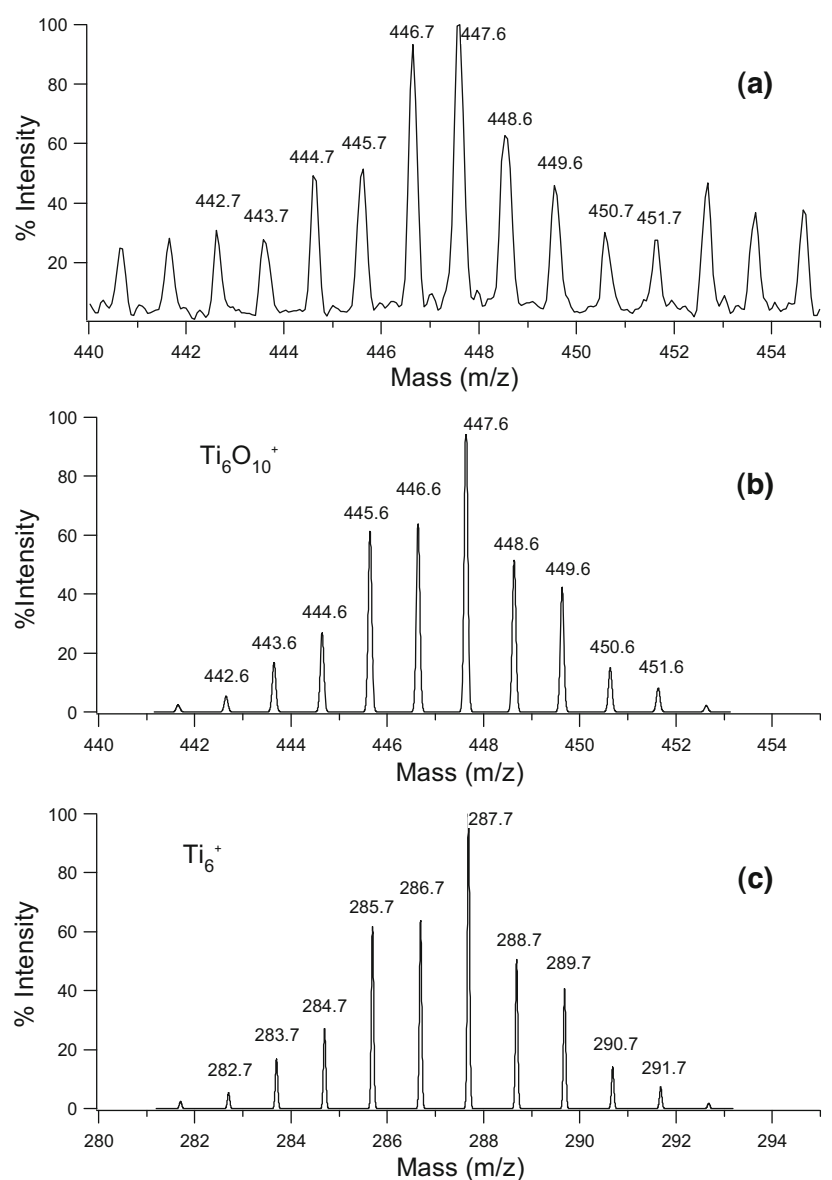

Figure 3. Isotopic distribution comparison for a $\mathrm{TiO}_{2}$ nanoparticle sample that has undergone size-selective precipitation. (a) Positive reflectron MALDI mass spectrum centered at $\mathrm{m} / \mathrm{z} 448$; (b) theoretical isotopic distribution of $\mathrm{Ti}_{6} \mathrm{O}_{10}^{+}$; (c) theoretical isotopic distribution of $\mathrm{Ti}_{6}^{+}$.

five stable isotopes: ${ }^{46} \mathrm{Ti}(10.8 \%),{ }^{47} \mathrm{Ti}(9.9 \%),{ }^{49} \mathrm{Ti}(7.5 \%)$, ${ }^{50} \mathrm{Ti}(7.3 \%)$, with ${ }^{48} \mathrm{Ti}(73.8 \%)$ being the most abundant; this unique isotopic pattern facilitates the assignment of titanium-containing species. Using LDI without any matrix also gave signals corresponding to titanium oxide cations. This is in accordance with the fact that $\mathrm{TiO}_{2}$ is a fairly strong UV absorber, and $\mathrm{TiO}_{2}$ itself has been used as a matrix for MALDI experiments [48-50]. The observation of similar results by MALDI and LDI without the presence of a matrix has some precedent; similar behavior was observed when studying ferrite nanoparticles [29] and rhenium halide nanoparticles [51].

Numerous detected peaks in the spectra showed isotopic clusters characteristic of titanium-containing ions. Careful review of the isotopic patterns revealed that these titanium oxide species were uniformly singly charged. Above $m / z 250$, titanium isotopic peak patterns exhibited considerable overlap, thus making the spectra rather complicated to interpret. Figure 3 shows the isotopic distribution comparison of the $\mathrm{m} / \mathrm{z}$ range from 440 to 455 centered at $m / z 448$. The top spectrum is the positive ion reflectron MALDI MS experimental result; the middle spectrum is the theoretical isotopic distribu- tion of $\mathrm{Ti}_{6} \mathrm{O}_{10}^{+}$; and the bottom one is the theoretical isotopic distribution of $\mathrm{Ti}_{6}^{+}$. The singly charged ions can be directly assigned from the experimental data as a result of the high resolution of the instrument in the reflectron mode used in this experiment. The experimental data deviate slightly from the theoretical isotopic distribution and some overlap with other desorbed ions at both ends of the isotopic pattern can be clearly seen.

Figure 4 shows the MALDI mass spectra from $\mathrm{m} / \mathrm{z}$ 250 to $\mathrm{m} / \mathrm{z} 5000$ acquired for three $\mathrm{TiO}_{2}$ nanoparticle preparations, each being characterized by a different size distribution. Upon MALDI irradiation, each monodispersed sample presented a broad normal-shaped distribution of ions with a single maximum that was analyzed and subjected to mathematical treatment. The smoothed peak maxima were determined to be around $m / z 1130$ (A), 1030 (B) and 520 (C) for samples of progressively decreasing cluster size, as determined by fractional crystallization. Possibly because of the fact that each spectrum represents data obtained from irradiation of multiple particles, the obtained maxima exhibited only minor variations (mean variation $=4.7 \pm$ $1.7 \%$ ) in replicate samples. Coupled to the peak shift, a narrowing of the peak shape is also observed as size becomes smaller. It should be noted that the major dithranol matrix peaks (that is, $m / z 225,226,227$, and 211) are well below the range of the smoothed peak maxima. Higher mass matrix peaks appear in only minor abundances, and thus they have a negligible influence on nanoparticle size calculations.

Varying the laser power changes the individual titanium oxide peak intensities without a significant change in the position and shape of the high-intensity broad normal-shaped MS peak maximum. The absence of $\mathrm{m} / \mathrm{z}$ shift suggests that titanium oxide nano-

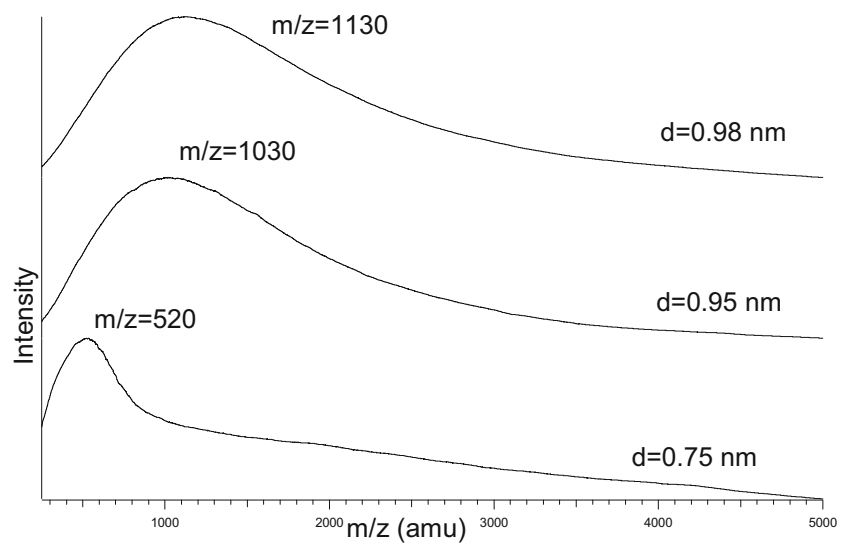

Figure 4. Positive ion reflectron mode MALDI mass spectra of $\mathrm{TiO}_{2}$ nanoparticles with progressively decreasing size as the result of size-selective precipitation. Dithranol was used as the matrix. Using the density value of anatase crystalline form, the diameters of the three samples were calculated to be: (A) $0.98 \mathrm{~nm},(B)$ $0.95 \mathrm{~nm}$, and (C) $0.75 \mathrm{~nm}$. Data processing was performed using IGOR Pro 4.07 (Wave Metrics, Lake Oswego, OR). LDI-TOF mass spectra yielded similar results. 
materials are ionized without the ligand shell. Even at lower laser powers, the capping material is most likely lost in the laser plume, as was previously observed for other nanocrystal measurements by LDI-TOF-MS [21, 27].

Employing certain assumptions, LDI- and MALDITOF-MS have found use for the determination of nanoparticle sizes [21, 26-28]. If the nanocrystals are presumed to be spherically shaped and the mass of attached protons or cations can be ignored, the diameter (d) of nanomaterials can be calculated by using the following equation:

$$
(\mathrm{m} / \mathrm{z})_{\exp }=(\pi / 6) N_{\mathrm{A}}\left(d^{3}\right) \rho / \mathrm{z}
$$

where $(m / z)_{\exp }$ is the smoothed peak maximum obtained from MALDI or LDI mass spectra; $N_{\mathrm{A}}$ is Avogadro's number; and $\rho$ and $z$ are the density of, and charge carried by, the nanoparticles, respectively.

Assuming $\mathrm{TiO}_{2}$ nanoparticles have the same density as the bulk $\mathrm{TiO}_{2}$, the densities $(\rho)$ of the two most important $\mathrm{TiO}_{2}$ crystalline forms, anatase and rutile, are $3.84 \times 10^{-21}$ and $4.26 \times 10^{-21} \mathrm{~g} / \mathrm{nm}^{3}$, respectively. Using the density value of the anatase crystalline form, the diameters of the three samples (Figure 4A-C) were calculated to be $0.98,0.95$, and $0.75 \mathrm{~nm}$, respectively. Thus, low-resolution MALDI-TOF peak maxima are shown to correlate with anatase cluster size, and the possibility of using MALDI-TOF-MS to estimate clusters size is affirmed. The size distributions of $\mathrm{TiO}_{2}$ nanoparticles obtained from MALDI-TOF-MS and Eq. 1 are in good agreement with our TEM observations.

Upon increasing the laser power, peaks below $\mathrm{m} / \mathrm{z}$ 200 progressively emerge, and these were subjected to PSD. Figure $5 \mathrm{~A}$ is the LDI-TOF mass spectrum of $\mathrm{TiO}_{2}$ nanoparticles showing the mass range centered at $\mathrm{m} / \mathrm{z}$ 167. Figure $5 \mathrm{~B}$ is the theoretical isotopic distribution of $\mathrm{Ti}_{2} \mathrm{O}_{3} \mathrm{Na}^{+}$, whereas Figure $5 \mathrm{C}$ is the PSD spectrum of the precursor ion $\left[\mathrm{Ti}_{2} \mathrm{O}_{3}+\mathrm{Na}\right]^{+}$at $m / z$ 167. Neutral loss of $\mathrm{Ti}_{2} \mathrm{O}_{3}$ yields $\mathrm{Na}^{+}$at $m / z$ 23. This demonstrates that MALDI-TOF and LDI-TOF peaks originating from titanium oxide nanoparticles can contain sodium (a ubiquitous contaminant).

Characterization of an isolated titanium oxide molecular cluster prepared by controlled hydrolysis of titanium tetraethoxide in the presence of methacrylic acid was previously performed by electrospray TOF-MS [30]. The cluster fragmentation patterns were carefully studied and the experimental results suggest that the core structures of the fragmentation products are analogous to those found in bulk titanium oxide materials. The polycondensation of $\mathrm{Ti}\left(\mathrm{OC}_{4} \mathrm{H}_{9}\right)_{4}$ has been studied by electrospray, LDI, and MALDI [52-54]. Several possible structures of the oligomers of $\mathrm{Ti}\left(\mathrm{OC}_{4} \mathrm{H}_{9}\right)_{4}$ detected by ES-MS using direct infusion of alcoholic solutions were given $[53,54]$. The LDI and MALDI mass spectra resulting from alcoholic preparations of $\mathrm{Ti}\left(\mathrm{OC}_{4} \mathrm{H}_{9}\right)_{4}$ also showed three series of peaks corresponding to ions
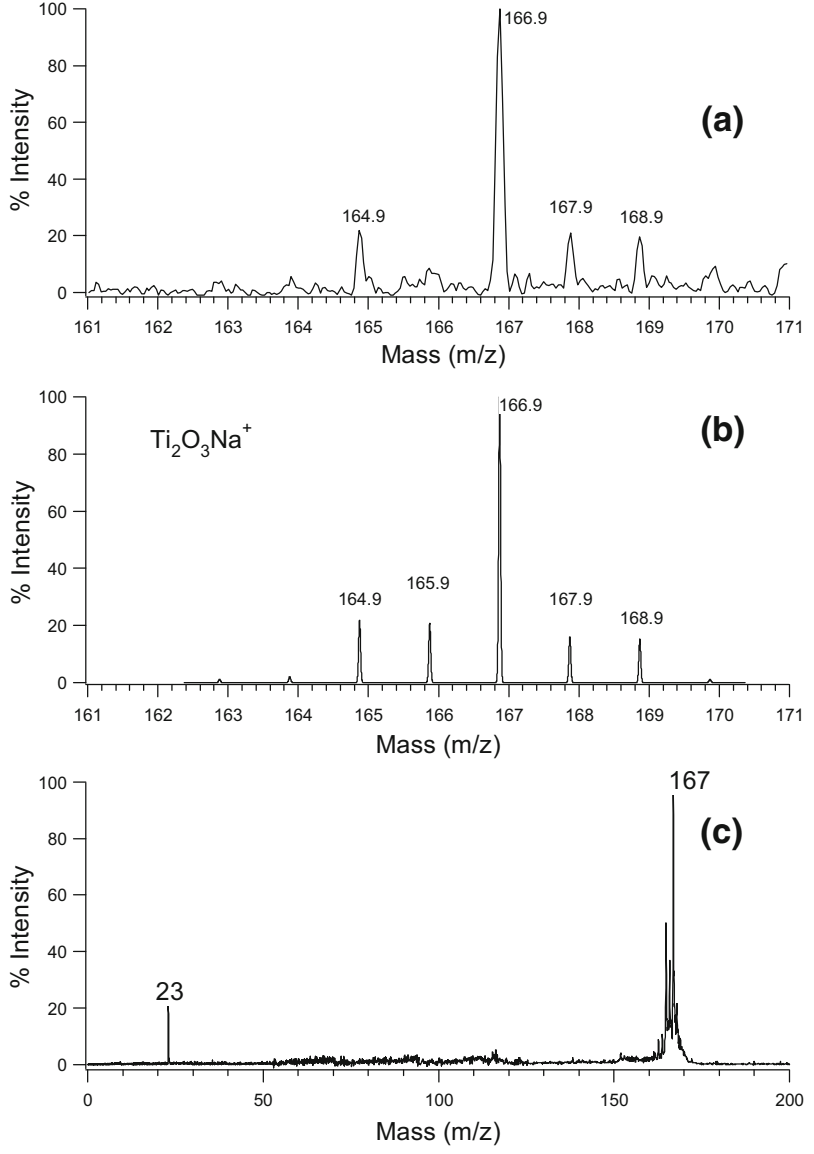

Figure 5. (a) LDI-TOF mass spectrum of $\mathrm{TiO}_{2}$ nanoparticles showing mass range centered at $m / z$ 167. (b) Theoretical isotopic distribution of $\mathrm{Ti}_{2} \mathrm{O}_{3} \mathrm{Na}^{+}$. (c) PSD spectrum of precursor ion $\left[\mathrm{Ti}_{2} \mathrm{O}_{3}+\mathrm{Na}\right]^{+}$at $m / z$ 167; neutral loss of $\mathrm{Ti}_{2} \mathrm{O}_{3}$ yields $\mathrm{Na}^{+}$at $\mathrm{m} / \mathrm{z}$ 23. This demonstrates that MALDI-TOF and LDI-TOF peaks originating from titanium oxide nanoparticles may contain sodium.

containing at least three titanium atoms [52]. Our mass spectra are more complex than those of previous reports [52-54], with titanium isotopic peak patterns spread from $\mathrm{m} / \mathrm{z} 200$ to around 3000. One major difference between those experiments and ours is that the previous studies focused on the hydrolysispolycondensation behavior of alcoholic solutions containing $\mathrm{Ti}\left(\mathrm{OC}_{4} \mathrm{H}_{9}\right)_{4}$, whereas we are interested in the $\mathrm{TiO}_{2}$ nanoparticles synthesized by the thermal solvent process.

It should be noted that the expected molecular ions of $\mathrm{Ti}\left(\mathrm{OC}_{4} \mathrm{H}_{9}\right)_{4}$ (for example, protonated at $\mathrm{m} / \mathrm{z} 340$ ) did not stand out in mass spectra because of their low abundances and because of the significant number of other species appearing in this region of the spectrum. Potentially, incomplete hydrolysis [6] of all butoxide ligands may be responsible for some of the background peaks. It is very likely that some proportion of the alkoxy groups will remain in the hydrolysates. Similarly, complete condensation of the alkoxide to $\mathrm{TiO}_{2}$ is very unlikely, and some proportion of the hydroxide groups formed during hydrolysis is likely to remain in 
the hydrolysates. Sample impurities and the complexity of resulting cluster compounds complicate interpretation, especially without separation of synthetic products [55].

\section{Conclusions}

We have shown that a stable $\mathrm{TiO}_{2}$ cluster suspension is produced by the thermal solvent process and clusters with different sizes are obtained by size selection. XRD patterns of clusters with sizes $<1 \mathrm{~nm}$ are very different from the principal peaks of the larger particles stemming from the extreme surface area-to-volume ratio. We successfully used MALDI-TOF-MS and LDITOF-MS to characterize ultrasmall $(<1 \mathrm{~nm})$ nanoparticles. Peak maxima observed in MALDI-TOF and LDITOF mass spectra were shown to correlate with nanoparticle size. The obtained size distributions of $\mathrm{TiO}_{2}$ nanoparticles are in good agreement with TEM measurements made on the identical samples. PSD analysis of inorganic nanomaterials has also been performed. PSD data demonstrate that MALDI-TOF and LDI-TOF peaks originating from titanium oxide nanoparticles may appear as sodium adducts. The ability to obtain detailed information concerning subnanometer titania nanoparticles has important implications for the continuing development of nanoparticle-based bactericidal agents. [36, 37, 38].

\section{Acknowledgments}

This work was supported by NSF Grant CHE-0518288 and a grant from ESA Biosciences, Inc. to R. B. Cole; NSF CAREER Program Grant DMR-0449580 and DARPA Grant HR0011-05-1-0031 to J. Fang; and by Louisiana Board of Regents HEF Grant 2001-06-08. The authors also thank Professor J. Tang for help in XRD measurements.

\section{References}

1. Fujishima, A.; Rao, T. N.; Tryk, D. A. Photocatalysts and Diamond Electrodes. Electrochim. Acta 2000, 45, 4683-4690.

2. Hoffmann, M. R.; Martin, S. T.; Choi, W. Y.; Bahnemann, D. W. Environmental Applications of Semiconductor Photocatalysis. Chem. Rev. 1995, 95, 69-96.

3. Linsebigler, A. L.; Lu, G. Q.; Yates, J. T. Photocatalysis on $\mathrm{TiO}_{2}$ Surfaces-Principles, Mechanisms, and Selected Results. Chem. Rev. 1995, 95, 735-758.

4. Garzella, C.; Comini, E.; Tempesti, E.; Frigeri, C.; Sberveglieri, G. TiO, Thin Films by a Novel Sol-Gel Processing for Gas Sensor Applications. Sens. Actuators B Chem. 2000, 68, 189-196.

5. Rao, K. N.; Murthy, M. A.; Mohan, S. Optical-Properties of ElectronBeam-Evaporated $\mathrm{TiO}_{2}$ Films. Thin Solid Films 1989, 176, 181-186.

6. Venz, P. A.; Kloprogge, J. T.; Frost, R. L. Chemically Modified Titania Hydrolysates: Physical Properties. Langmuir 2000, 16, 4962-4968.

7. Oregan, B.; Gratzel, M. A Low-Cost, High-Efficiency Solar-Cell Based on Dye-Sensitized Colloidal $\mathrm{TiO}_{2}$ Films. Nature 1991, 353, 737-740.

8. Hagfeldt, A.; Gratzel, M. Light-Induced Redox Reactions in Nanocrystalline Systems. Chem. Rev. 1995, 95, 49-68.

9. Henrich, V. E.; Cox, P. A. The Surface Science of Metal Oxides; Cambridge Univ. Press: New York, 1994

10. Pacchioni, G.; Ferrari, A. M.; Bagus, P. S. Cluster and Band Structure Ab Initio Calculations on the Adsorption of $\mathrm{CO}$ on Acid Sites of the $\mathrm{TiO}_{2}$ (110) Surface. Surf. Sci. 1996, 50, 159-175.

11. Sousa, C.; Illas, F. Ionic-Covalent Transition in Titanium-Oxides. Phys Rev. B 1994, 50, 13974-13980.

12. Hagfeldt, A.; Siegbahn, H.; Lindquist, S. E.; Lunell, S. Semiempirical Calculations of $\mathrm{TiO}_{2}$ (Rutile) Clusters. Int. J. Quantum Chem. 1992, 44, $477-495$.
13. Doeuff, S.; Dromzee, Y.; Taulelle, F.; Sanchez, C. Synthesis and SolidState and Liquid-State Characterization of a Hexameric Cluster of Titanium (IV)- $\mathrm{Ti}_{6}\left(\mu_{2}-\mathrm{O}\right)_{2}\left(\mu_{3}-\mathrm{O}\right)_{2}\left(\mu_{2}-\mathrm{OC}_{4} \mathrm{H}_{9}\right)_{2}\left(\mathrm{OC}_{4} \mathrm{H}_{9}\right)_{6}\left(\mathrm{OCOCH}_{3}\right)_{8}$. Inorg. Chem. 1989, 28, 4439-4445.

14. Schubert, U.; Arpac, E.; Glaubitt, W.; Helmerich, A.; Chau, C. Primary Hydrolysis Products of Methacrylate-Modified Titanium and Zirconium Alkoxides. Chem. Mater. 1992, 4, 291-295.

15. Wilcoxon, J. P.; Martin, J. E.; Provencio, P. Size Distributions of Gold Nanoclusters Studied by Liquid Chromatography. Langmuir 2000, 16, 9912-9920.

16. Cullity, B. D. Elements of X-ray Diffraction; Addison-Wesley: Reading, MA, 1978.

17. Kubler, B.; Millon, E.; Gaumet, J. J.; Muller, J. F. Formation of High mass Cn Clusters $(\mathrm{n}>100)$ by Laser Ablation/Desorption Coupled with Mass Spectrometry. Fullerene Sci. Technol. 1996, 4, 1247-1261.

18. Hummelen, J. C.; K night, B.; Pavlovich, J.; Gonzalez, R.; Wudl, F. Isolation of the Heterofullerene $\mathrm{C}_{59} \mathrm{~N}$ as Its Dimer $\left(\mathrm{C}_{59} \mathrm{~N}\right)_{2}$. Science 1995, $269,1554-1556$

19. Lafargue, P. E.; Gaumet, J. J.; Muller, J. F.; Labrosse, A. Laser Ablation of Silica: Study of Induced Clusters by Fourier Transform Ion Cyclotron Resonance Mass Spectrometry. J. Mass Spectrom. 1996, 31, 623-632.

20. Kasuya, A.; Sivamohan, R.; Barnakov, Y. A.; Dmitruk, I. M.; Nirasawa, T.; Romanyuk, V. R.; Kumar, V.; Mamykin, S. V.; Tohji, K.; Jeyadevan, B.; Shinoda, K.; Kudo, T.; Terasaki, O.; Liu, Z.; Belosludov, R. V. Sundararajan, V.; Kawazoe, Y. Ultra-stable Nanoparticles of CdSe Revealed from Mass Spectrometry. Nat. Mater. 2004, 3, 99-102.

21. Khitrov, G. A.; Strouse, G. F. ZnS Nanomaterial Characterization by MALDI-TOF Mass Spectrometry. J. Am. Chem. Soc. 2003, 125, 1046510469.

22. Gaumet, J. J.; Strouse, G. F. Nanospray Mass Spectrometry Technique for Analyzing Nanomaterials from Molecular Precursors up to $1.5 \mathrm{~nm}$ in Diameter Clusters. Mater. Sci. Eng. C 2002, 19, 299-304.

23. Gaumet, J. J.; Khitrov, G. A.; Strouse, G. F. Mass Spectrometry Analysis of the $1.5 \mathrm{~nm}$ Sphalerite-CdS Core of $\left[\mathrm{Cd}_{32} \mathrm{~S}_{14}\left(\mathrm{SC}_{6} \mathrm{H}_{5}\right)_{36} \mathrm{DMF}_{4}\right]$. Nano. Lett. 2002, 2, 375-379.

24. Gaumet, J. J.; Strouse, G. F. Electrospray Mass Spectrometry of Semiconductor Nanoclusters: Comparative Analysis of Positive and Negative Ion Mode. J. Am. Soc. Mass Spectrom. 2000, 11, 338-344.

25. Schaaff, T. G.; Shafigullin, M. N.; Khoury, J. T.; Vezmar, I.; Whetten, R. L. Properties of a Ubiquitous $29 \mathrm{kDa}$ Au:SR Cluster Compound. J. Phys. Chem. B 2001, 105, 8785-8796.

26. Whetten, R. L.; Khoury, J. T.; Alvarez, M. M.; Murthy, S.; Vezmar, I.; Wang, Z. L.; Stephens, P. W.; Cleveland, C. L.; Luedtke, W. D.; Landman, U. Nanocrystal Gold Molecules. Adv. Mater. 1996, 8, 428-433.

27. Arnold, R. J.; Reilly, J. P. High-resolution Time-of-Flight Mass Spectra of Alkanethiolate-coated Gold Nanocrystals. J. Am. Chem. Soc. 1998, 120, $1528-1532$

28. Vezmar, I.; Alvarez, M. M.; Khoury, J. T.; Salisbury, B. E.; Shafigullin, M. N.; Whetten, R. L. Z. Cluster Beams from Passivated Nanocrystals. Z. Phys. D: At. Mol. Clusters 1997, 40, 147-151.

29. d'Avray, A. T. D.; Carpenter, E. E.; O'Connor, C. J.; Cole, R. B Characterization of Ferrite Nanoparticles by Laser Desorption/ Ionization Mass Spectrometry. Eur. Mass Spectrom. 1998, 4, 441-449.

30. Khitrov, G. A.; Strouse, G. F.; Gaumet, J. J. Characterization of $\mathrm{Ti}_{6} \mathrm{O}_{4}\left(\mathrm{O}_{2} \mathrm{C}_{4} \mathrm{H}_{5}\right)_{8}\left(\mathrm{OCH}_{2} \mathrm{CH}_{3}\right)_{8}$ by Electrospray Time of Flight Mass Spectrometry. J. Am. Soc. Mass Spectrom. 2004, 15, 260-267.

31. Mori, H.; Lanzendorfer, M. G.; Muller, A. H. E.; Klee, J. E. Silsesquioxane-based Nanoparticles Formed via Hydrolytic Condensation of Organotriethoxysilane Containing Hydroxy Groups. Macromolecules 2004, 37, 5228-5238.

32. Alves, S.; Kalberer, M.; Zenobi, R. Direct Detection of Particles Formed by Laser Ablation of Matrices during Matrix-assisted Laser Desorption/ Ionization. Rapid Commun. Mass Spectrom. 2003, 17, 2034-2038.

33. Bauer, F.; Sauerland, V.; Ernst, H.; Glasel, H. A.; Naumov, S.; Mehnert, R. Preparation of Scratch- and Abrasion-resistant Polymeric Nanocomposites by Monomer Grafting onto Nanoparticles, 4. Application of MALDI-TOF Mass Spectrometry to the Characterization of Surface Modified Nanoparticles. Macromol. Chem. Phys. 2003, 204, 375-383.

34. Colton, R.; Dagostino, A.; Traeger, J. C. Electrospray Mass Spectrometry Applied Inorganic and Organometallic Chemistry. Mass Spectrom. Rev. 1995, 14, 79-106.

35. Gatlin, C. L.; Turecek, F. Electrospray Ionization Mass Spectrometry: Fundamentals, Instrumentation, and Applications; Cole, R. B., Ed.; WileyInterscience: New York, 1997.

36. Traeger, J. C. Electrospray Mass Spectrometry of Organometallic Compounds. Int. J. Mass. Spectrom. 2000, 200, 387-401.

37. Lover, T.; Henderson, W.; Bowmaker, G. A.; Seakins, J. M.; Cooney R. P. Electrospray Mass Spectrometry of Thiophenolate-capped Clusters of CdS, CdSe, and ZnS and of Cadmium and Zinc Thiophenolate Complexes: Observation of Fragmentation and Metal, Chalcogenide, and Ligand Exchange Processes. Inorg. Chem. 1997, 36, 3711-3723.

38. Lover, T.; Henderson, W.; Bowmaker, G. A.; Seakins, J. M.; Cooney, R. P. Functionalization and Capping of a CdS Nanocluster: A Study of Ligand Exchange by Electrospray Mass Spectrometry. Chem. Mater. 1997, 9, 1878-1886.

39. Spengler, B.; Kirsch, D.; Kaufmann, R. Metastable Decay of Peptides and Proteins in Matrix-assisted Laser-Desorption Mass-Spectrometry. Rapid Commun. Mass Spectrom. 1991, 5, 198-202. 
40. Spengler, B.; Kirsch, D.; Kaufmann, R.; Jaeger, E. Peptide Sequencing by Matrix-Assisted Laser-Desorption Mass-Spectrometry. Rapid Commun. Mass Spectrom. 1992, 6, 105-108.

41. Mitsuhashi, T.; Kleppa, O. J. Transformation Enthalpies of the $\mathrm{TiO}_{2}$ Polymorphs. J. Am. Ceram. Soc. 1979, 62, 356-357.

42. Cheng, H. M.; Ma, J. M.; Zhao, Z. G. Qi, L. M. Hydrothermal Preparation of Uniform Nanosize Rutile and Anatase Particles. Chem. Mater. $1995,7,663-671$.

43. International Centre for Diffraction Data (ICDD, formerly JCPDS), File no. 21-1272; ICDD: Newtown Square, PA

44. Chen, L. X.; Rajh, T.; Jager, W.; Nedeljkovic, J.; Thurnauer, M. C. X-ray Absorption Reveals Surface Structure of Titanium Dioxide Nanoparticles. J. Synchrotron. Radiat. 1999, 6, 445-447.

45. Chen, L. X.; Rajh, T.; Wang, Z. Y.; Thurnauer, M. C. XAFS Studies of Surface Structures of $\mathrm{TiO}_{2}$ Nanoparticles and Photocatalytic Reduction of Metal Ions. J. Phys. Chem. B 1997, 101, 10688-10697.

46. Rajh, T.; Poluektov, O.; Dubinski, A. A.; Wiederrecht, G.; Thurnauer, M. C.; Trifunac, A. D. Spin Polarization Mechanisms in Early Stages of Photoinduced Charge Separation in Surface-modified $\mathrm{TiO}_{2}$ Nanoparticles. Chem. Phys. Lett. 2001, 344, 31-39.

47. Naicker, P. K.; Cummings, P. T.; Zhang, H. Z.; Banfield, J. F. Characterization of Titanium Dioxide Nanoparticles Using Molecular Dynamics Simulations. J. Phys. Chem. B 2005, 109, 15243-15249.

48. Chen, C. T.; Chen, Y. C. Molecularly Imprinted $\mathrm{TiO}_{2}$-Matrix-assisted Laser Desorption/Ionization Mass Spectrometry for Selectively Detecting alpha-Cyclodextrin. Anal. Chem. 2004, 76, 1453-1457.
49. Chen, C. T.; Chen, Y. C. Desorption/Ionization Mass Spectrometry on Nanocrystalline Titania Sol-Gel-deposited Films. Rapid Commun. Mass Spectrom. 2004, 18, 1956-1964.

50. Kinumi, T.; Saisu, T.; Takayama, M.; Niwa, H. Matrix-assisted Laser Desorption/Ionization Time-of-Flight Mass Spectrometry Using an inorganic Particle Matrix for Small Molecule Analysis. J. Mass Spectrom. 2000, 35, 417-422.

51. Dopke, N. C.; Treichel, P. M.; Vestling, M. M. Matrix-assisted Laser Desorption/Ionization Time-of-Flight Mass Spectrometry (MALDI-TOF MS) of Rhenium(III) Halides: A Characterization Tool for Metal Atom Clusters. Inorg. Chem. 1998, 37, 1272-1277.

52. Seraglia, R.; Armelao, L.; Cristoni, S.; Gross, S.; Tondello, E.; Traldi, P. Matrix-assisted Laser Desorption/Ionisation Mass Spectrometry in the Study of Polycondensation of $\mathrm{Ti}(\mathrm{OBu}-\mathrm{n})_{4}$ in the Presence of $\mathrm{Si}(\mathrm{OEt})_{4}$. Rapid Commun. Mass Spectrom. 2003, 17, 2649-2654.

53. Cristoni, S.; Armelao, L.; Gross, S.; Tondello, E.; Traldi, P. Electrospray Ionization in the Study of the Polycondensation of $\mathrm{Ti}\left(\mathrm{O}-\mathrm{i}-\mathrm{C}_{3} \mathrm{H}_{7}\right)_{4}$ and $\mathrm{Ti}\left(\mathrm{O}-\mathrm{n}-\mathrm{C}_{4} \mathrm{H}_{9}\right)_{4}$. Rapid Commun. Mass Spectrom. 2000, 14, 662-668.

54. Cristoni, S.; Armelao, L.; Gross, S.; Tondello, E.; Traldi, P. Electrospray Ionization in the Study of Sol-Gel Processes: The Polycondensation of $\mathrm{Ti}(\mathrm{O}-\mathrm{n}-\mathrm{Bu})_{4}$ in the Presence of $\mathrm{Si}(\mathrm{OEt})_{4}$. Rapid Commun. Mass Spectrom. 2001, 15, 386-392.

55. Schaaff, T. G. Laser Desorption and Matrix-assisted Laser Desorption/ Ionization Mass Spectrometry of 29-kDa Au:SR Cluster Compounds. Anal. Chem. 2004, 76, 6187-6196. 